\title{
École et religion
}

Introduction

Dominique Borne

\section{CpenEdition}

Journals

Édition électronique

URL : http://journals.openedition.org/ries/1431

DOI : $10.4000 /$ ries. 1431

ISSN : 2261-4265

Éditeur

Centre international d'études pédagogiques

Édition imprimée

Date de publication : 1 septembre 2004

Pagination : 21-25

ISBN : 978-2-85420-561-8

ISSN : 1254-4590

Référence électronique

Dominique Borne, « École et religion », Revue internationale d'éducation de Sèvres [En ligne], 36 | septembre 2004, mis en ligne le 18 novembre 2011, consulté le 22 septembre 2020. URL : http:// journals.openedition.org/ries/1431; DOI : https://doi.org/10.4000/ries.1431 


\section{École et religion}

\section{Introduction}

\section{Dominique Borne}

Pourquoi ouvrir, aujourd'hui, cette réflexion sur les enjeux de la présence - ou de l'absence - des religions à l'école? Les récents débats francofrançais pourraient certes inciter à s'intéresser à nos voisins: ont-ils des problèmes comparables aux nôtres? Les perspectives ici ouvertes entendent dépasser largement la conjoncture française. S'interroger sur le religieux à l'école, ce n'est pas seulement se pencher sur les signes portés par les élèves, c'est examiner, dans un contexte national précis, le statut des écoles (publiques? privées? privées confessionnelles?), c'est analyser l'enseignement dispensé: cours de religion? D'histoire des religions? Pluralisme? C'est aussi se demander : qui enseigne? Qui contrôle ces enseignements? Ces questions, nous les posons à un moment où, en Europe, malgré, ici ou là, quelques nostalgies des spiritualités d'autrefois reçues en héritage, s'accélère une sécularisation des sociétés entamée depuis plus de deux siècles. Cette Europe, où la pratique religieuse est très minoritaire, reçoit de plein fouet le choc de manifestations religieuses fortes, et parfois dogmatiques, celles de l'islam. Certains courants de l'islam souhaiteraient en effet inverser le mouvement de sécularisation et réinstaurer un contrôle religieux des sociétés. Le choix des exemples que nous présentons est justifié par ce contexte : la base de notre réflexion est l'Europe, les États envisagés donnent une idée de sa diversité géoculturelle, mais nous avons choisi en contrepoint des États méditerranéens qui relèvent d'autres héritages. La Turquie est entre deux mondes, à la fois laïque et musulmane; le Liban offre l'exemple de cohabitation de communautés chrétiennes et musulmanes, au Maroc la monarchie elle-même est directement liée à l'islam. Nous avons choisi Israël, enfin, afin d'interroger les pratiques d'un État singulier dont on oublie trop souvent qu'il regroupe non seulement des juifs mais aussi des citoyens arabes chrétiens et musulmans.

Cette brève introduction au dossier ne peut en traduire tous les aspects. On lira, dans les articles, la complexité des problèmes de statut qu'il n'est pas possible de détailler ici. Un seul constat d'ensemble : presque partout il existe, aux côtés de l'enseignement entièrement contrôlé et organisé par les États, un enseignement privé pour lequel la dimension religieuse est souvent un principe d'organisation. Cependant, les différences sont moins sensibles entre le privé et le public d'un même État que celles qui apparaissent d'un État à l'autre. 
Autrement dit, l'école est plus marquée par les héritages religieux et culturels que par les structures juridiques.

Le premier élément d'analyse que nous souhaitons mettre en évidence oppose la France à tous les autres États ici étudiés. Pour la France républicaine, tout ce qui relève des croyances est de l'ordre du privé; les croyances sont respectées mais leur enseignement ne peut trouver place à l'école publique. Ailleurs, en Europe et autour de la Méditerranée, dans les écoles organisées par l'État, l'enseignement des croyances est présent d'une manière ou d'une autre. Cette situation est relativement nouvelle. Les oppositions entre les États européens étaient plus importantes il y a une vingtaine d'années : au temps de l'URSS et avant la chute du Mur, un enseignement anti-religieux, et plus précisément parfois des cours d'athéisme, étaient proposés dans les écoles de l'Europe de l'Est. Aujourd'hui des cours d'instruction religieuse organisés et financés par l'État, mais dont les contenus sont contrôlés par l'Église catholique sont dispensés en Pologne. En Russie, les écoles proposent des cours d'histoire des religions mais aussi des leçons de «culture orthodoxe» expertisés par l'Église. Ce «retour du religieux» en Europe de l'Est contribue donc à homogénéiser les espaces ici présentés. Cette première affirmation est cependant trompeuse : les croyances sont présentes à l'école dans l'ensemble des États ici envisagés mais elles ne le sont pas de la même manière. En Europe en effet, le pluralisme religieux est, à l'école, la règle générale; ce pluralisme est encore naturellement présent au Liban, où l'équilibre des communautés est constitutif de l'État, mais il disparaît au Maroc comme en Egypte.

En Europe, même quand la nation se reconnaît volontiers dans le message porté par une Église, cette Église ne porte plus le monopole du religieux à l'école. L'exemple grec est éclairant : le but de l'éducation, dit l'article 16 de la Constitution, est de développer «la conscience nationale et religieuse des Grecs». On sait que l'orthodoxie définit la nation elle-même, on observe cependant les débuts d'une sécularisation de cet enseignement, la possibilité de s'y soustraire, l'autorisation théorique donnée aux non orthodoxes d'assurer l'enseignement religieux. Pour évoquer un autre exemple, dans un climat nordique et protestant fort différent, l'Église évangélique luthérienne est toujours nationale au Danemark mais, à l'école, l'enseignement religieux n'est pas contrôlé par cette Église et il respecte le pluralisme. La situation est d'ailleurs la même dans les départements français (Alsace et Moselle) qui, soumis à l'Allemagne au moment de la Séparation de l'Église et de l'État en 1905, sont toujours sous le régime du Concordat : un enseignement religieux est dispensé dans les établissements scolaires, il n'est pas obligatoire et respecte le pluralisme.

Cette volonté de pluralisme glisse même dans certains cas vers des formes de communautarisme. Ainsi de l'exemple britannique : d'une part un très grand nombre d'établissements confessionnels sont financés par l'État, 
d'autre part, dans les établissements non confessionnels, l'étude des grandes religions est organisé; leur enseignement est assuré par des professeurs rémunérés par l'État, des programmes de référence qui servent de base à l'établissement des programmes locaux ont été élaborés pour six traditions religieuses, le christianisme, le judaïsme, le bouddhisme, l'hindouisme et la religion sikh. Chacun ainsi reconnaît sa paroisse et peut se retrouver entre soi, l'État britannique attendant de l'éducation religieuse, comme l'écrit Robert Jackson «qu'elle contribue au développement spirituel, moral, social et culturel des élèves et qu'elle joue un rôle significatif dans l'éducation à la citoyenneté ». L'ensemble de l'Europe n'accepterait pas cette juxtaposition organisée des spiritualités mais on peut penser que la plus grande partie des États souscriraient à ces finalités : soit parce que la religion fait partie du patrimoine national, de la culture commune, soit par volonté d'enraciner un principe spirituel en l'installant comme la base indispensable de toute éducation morale. Les Anglais vont encore plus loin en estimant qu'un bon croyant, quelle que soit sa croyance, doit faire un bon citoyen. Dans le même sens, de nombreux Länder inscrivent la dimension religieuse au cour de la formation des élèves. Dès 1949, la Loi fondamentale de la République fédérale précise que l'instruction religieuse est «une matière d'enseignement régulière», à charge pour les Länder d'organiser cet enseignement en liaison avec les Églises. En Allemagne, le pluralisme est naturel puisque deux confessions chrétiennes se partageaient l'espace germanique. Le problème, aujourd'hui, se pose de l'éventuelle extension de ce pluralisme à l'islam, huit cent mille élèves d'origine turque étant scolarisés en Allemagne. L'exemple allemand confirme cette tendance d'un usage des religions comme base d'une éducation : le Land du Brandebourg n'a-t-il pas tenté, en 1996, d'instaurer une nouvelle discipline LebensgestaltungEthik-Religionskunde, que l'on pourrait traduire par «conception de vieéthique-religion»?

Cette évolution européenne est compréhensible si on la replace dans la longue durée des relations entre les Églises et les nations. L'évolution générale vers la liberté religieuse, et donc le pluralisme, a été sanctionnée par le Concile de Vatican II dans les années 1960 ; elle a accompagné la sécularisation générale des sociétés : les deux phénomènes expliquent la présence maintenue des références spirituelles dans les écoles et le relativisme - ou la tolérance - vis-àvis de l'ensemble des expressions religieuses. Dans la plupart des écoles des États européens, les parents peuvent ainsi choisir les fondements de la morale enseignée à leurs enfants. Ces fondements peuvent être, ou non, confessionnels. L'Espagne, autrefois fermement catholique et monarchique, est, depuis les années 1970, symbolique de ces transformations. Les élèves peuvent choisir entre des cours de religion dispensés par des professeurs choisis par l'Église ou un enseignement d'histoire des religions. Rappelons enfin que l'affirmation croisée de la liberté religieuse et des principes spirituels comme fondements de 
la nation est constitutive des États-Unis d'Amérique. La place de la religion à l'école traduit bien ce double fondement.

La situation, on le sait, est fort différente en France; les débats récents ont encore renforcé cette différence. À l'origine se place la construction même de la nation et l'idéologie de la République. En ce domaine, la Révolution française a introduit la fracture décisive : elle rejette dans le passé révolu la tradition monarchique mais ne met pas fin au conflit fondateur qui se poursuit tout au long du XIX ${ }^{\mathrm{e}}$ siècle. Jusqu'au début des années 1880, deux nations s'opposent; l'histoire, instrumentalisée, oppose symboliquement les fils de Vercingétorix aux fils de Clovis. Les fils du résistant gaulois refusent de courber la tête sur les fonds baptismaux, les fils du fier Sicambre acceptent le baptême de la royauté. L'école est fondée au cœur de ces conflits; elle en porte la marque. Elle est laïque parce qu'elle veut former des citoyens qui résisteront aux homélies des prêtres hostiles à la République. La victoire et l'enracinement de la République se sont donc naturellement appuyés sur l'École. Ainsi, alors même que l'école de Guizot acceptait encore l'éducation religieuse, l'école de Jules Ferry la rejette hors de l'école et invente une morale laïque de substitution. L'enseignement, en France, est laïc. Cette affirmation engage même l'école privée quand elle passe contrat avec l'État : l'enseignement dispensé dans les classes est alors identique à celui du public. La dimension religieuse se réfugie en marge, dans le "caractère propre» de l'établissement. On ne peut faire confiance à personne d'autre qu'à la République pour former des citoyens.

La Turquie est un bon pays de transition pour aborder les rivages de la Méditerranée : la République fondée par Mustafa Kemal naît d'une rupture avec le Califat, elle est donc laïque et très inspirée du modèle français. Faut-il pour autant organiser à l'école des cours de religion? N'est-il pas dangereux de laisser à d'autres, à l'extérieur de l'école, la possibilité de garder influence? La religion ne serait-elle pas un bon moyen pour détourner la jeunesse des courants gauchistes? Mais quand, en 1982, la religion devient obligatoire à l'école, c'est parce qu'elle apparaît comme le meilleur ciment national. Les débats pour autant ne cessent pas où partisans d'un islam modéré, conciliable avec la démocratie, et fondamentalistes s'opposent. L'exemple du Liban, multiculturel, nous montre que d'autres voies seraient peut-être possibles; il est vrai que nous y retrouvons sans surprise la tradition ottomane de juxtaposition des communautés. La Constitution rend "hommage au Très-Haut», assure le respect des «intérêts religieux des populations», affirme "le droit des communautés d'avoir leurs écoles». Mais les efforts pour construire sur ces bases un manuel commun de culture - et non d'instruction - religieuse restent encore isolés. Notons, en écho, qu'en Allemagne, dans le Brandebourg, l'Église évangélique souhaiterait une coopération œcuménique des confessions chrétiennes et un enseignement spirituel «supra confessionnel». On voit bien, au Liban, comment un enseignement non pas sans doute des religions mais du 
religieux, une «relation historique et factuelle», pourraient contribuer à la légitimité historique des communautés et donc à leur coexistence pacifique. L'enjeu n'est-il pas comparable en Israël? Le rapport à la Bible, ici, est aussi un rapport à l'histoire et un rapport à l'hébreu; comment alors distinguer le religieux du national? Dans ces conditions, l'école est-elle laïque? Et les quatre cent mille élèves arabes? L'enseignement qui leur est dispensé tente de concilier les «fondements de la culture arabe» et la «connaissance de la culture juive». On mesure les difficultés et les contradictions de l'édifice si l'on ajoute l'existence d'écoles religieuses juives, souvent ultra orthodoxes.

Dans les derniers exemples envisagés, l'empreinte islamique marque directement l'école. Il s'agit, nous dit-on à propos du Maroc, d'islamiser la société. L'arabisation de l'enseignement, rejet de la langue du colonisateur, a été parallèle à son islamisation. En Égypte, «l'islam est la religion de l'État, les principes de la loi islamique constituent la source principale de législation». La mémorisation du Coran est une des finalités de l'école égyptienne; des concours couronnent les élèves les plus méritants. Certes l'État garantit la liberté de croyance et de culte mais tout prosélytisme pour une autre religion que l'islam est interdit. L'exemple marocain démontre les hésitations du pouvoir, alors même que les élites du pays confient leurs enfants au très important réseau d'établissements français. Le religieux a été, comme en Turquie naguère, considéré comme un moyen d'éviter la contestation politique et sociale. La montée de l'islamisme, les récents attentats de Casablanca provoquent aujourd'hui de nouvelles prises de conscience; mais est-il possible, dans le contexte marocain, de mettre en cause la présence du religieux à l'école?

Deux remarques nous permettront de conclure ou plutôt, à l'aide des éléments du dossier ici rassemblés, d'inviter à une réflexion plus approfondie. L'écart entre les pays méditerranéens musulmans et les États européens réside bien dans l'affirmation du caractère englobant de l'islam alors que les Chrétiens ont admis les conséquences de la reconnaissance de la liberté religieuse. Le second point porte sur les contenus des enseignements : le panorama européen nous offre trois possibilités. La version française relègue l'enseignement des croyances dans la sphère du privé et tente de construire un enseignement culturel et distancié du fait religieux. Mais elle propose une morale laïque de substitution. La version européenne la plus commune admet la présence de l'enseignement des croyances, souvent dans leur diversité, et autorise à choisir sa morale citoyenne et humaniste ou religieuse. Ici ou là, enfin, on voit poindre l'organisation de communautés dont l'identité religieuse peut s'affirmer dans les écoles. 